ARTICLE

\title{
Insertion of ammonia into alkenes to build aromatic $N$-heterocycles
}

\author{
Shuai Liu ${ }^{1,2} \&$ Xu Cheng (ib) ${ }^{1,3 凶}$
}

\begin{abstract}
Ammonia is one of the most abundant and simple nitrogen sources with decent stability and reactivity. Direct insertion of ammonia into a carbon skeleton is an ideal approach to building valuable $\mathrm{N}$-heterocycles for extensive applications with unprecedented atom and step economy. Here, we show an electrochemical dehydrogenative method in which ammonia is inserted directly into alkenes to build aromatic $N$-heterocycles in a single step without the use of any external oxidant. This new approach achieves 98-99.2\% atom economy with hydrogen as the only byproduct. Quinoline and pyridine with diverse substitutions are readily available. In this work, electrochemistry was used to drive a 4-electron oxidation reaction that is hard to access by other protocols, providing a parallel pathway to nitrene chemistry. In a tandem transformation that included three distinct electrochemical processes, the insertion of ammonia further showcased the tremendous potential to manipulate heterocycles derived from Hantzsch ester to diazine via pyridine and pyrrole.
\end{abstract}

\footnotetext{
${ }^{1}$ Institute of Chemistry and Biomedical Sciences, Jiangsu Key Laboratory of Advanced Organic Materials, School of Chemistry and Chemical Engineering, National Demonstration Center for Experimental Chemistry Education, Nanjing University, Nanjing 210023, China. ${ }^{2}$ School of Materials and Chemical Engineering, Xuzhou University of Technology, Xuzhou 221018, China. ${ }^{3}$ State Key Laboratory of Elemento-organic Chemistry, Nankai University, Tianjin 300071, China. 凶email: chengxu@nju.edu.cn
} 
A romatic $N$-heterocycles are common moieties in natural products $^{1}$, and they have been extensively applied to pharmaceutical design ${ }^{2}$. The classic syntheses of aromatic $N$-heterocycles are frequently conducted with condensation reactions using pre-oxidized materials. For example, in early efforts to synthesize isoquinoline from indene, oxidation cleavage of alkenes using ozone $e^{3,4}$ or $\mathrm{OsO}_{4}{ }^{5}$ was necessary, resulting in a limited scope of functionality (Fig. 1a) ${ }^{6}$. However, the insertion of heteroatoms into the carbon skeleton exhibits multiple advantages, including atom/step economy, oxidation-labile functional group (Fg) tolerance, and unexplored selectivity (Fig. 1b). However, it is difficult to find a method as efficient as oxidation for cleaving $\mathrm{C}-\mathrm{C}$ bonds, especially the bonds of alkenes and alkynes. Such an intrinsic obstacle makes the direct insertion of heteroatoms into alkenes to build heterocycles an elusive goal. To regulate the oxidation state of organic molecules, the dehydrogenation reaction is a complementary route to the oxygenation reaction ${ }^{7-21}$. Dehydrogenative cross-coupling exhibits a unique ability to achieve oxidative bond formation in the absence of external oxidants $^{22-26}$. In particular, the electrochemical protocol demonstrates its intrinsic potential to drive dehydrogenative crosscoupling reactions with cathodic hydrogen evolution ${ }^{27-30}$. As one of the most important C-heteroatom connections, considerable efforts have been made to construct $\mathrm{C}-\mathrm{N}$ bonds, including electrochemical protocols ${ }^{31-33}$. In recent years, the electrochemical dehydrogenative intermolecular construction of $\mathrm{C}-\mathrm{N}$ bonds has witnessed tremendous progress, for example, in reactions of aromatic C-H amination ${ }^{34-43}$, benzylic C-H amination ${ }^{44-46}$, alkyne amination $^{47}$, alkene azidation ${ }^{48}$, alkane amination ${ }^{49}$, aromatic C$\mathrm{X} / \mathrm{N}-\mathrm{H}$ cross coupling ${ }^{50-53}$, alkene aziridination ${ }^{49,54-59}$, and other innovations ${ }^{60}$. Despite these achievements, electricity has not fulfilled the task of sewing $\mathrm{NH}_{3}$ and alkene to aromatic $\mathrm{N}$ heterocycles.

In this work, we report the insertion of ammonia into carbon skeletons to build diverse aromatic $N$-heterocycles via a multiple electron transfer pathway involving hydrogen evolution with up to $99.2 \%$ theoretical atom economy.

\section{Results}

Optimization of insertion of ammonia into indene. In the initial attempt, 1a was adopted as the substrate with the conjugated tetrasubstituted alkene as the target bond to insert a nitrogen atom with ammonia (Table 1 ) at $0{ }^{\circ} \mathrm{C}$. The first observed insertion product $2 \mathrm{a}$ had a $16 \%{ }^{1} \mathrm{H}$ NMR yield when graphite felt (GF) was used as the electrodes and methanol was used as the solvent (entry 1). Pt (entry 2) and Ag (entry 3) were applied as cathodes to enhance the evolution of hydrogen, and the

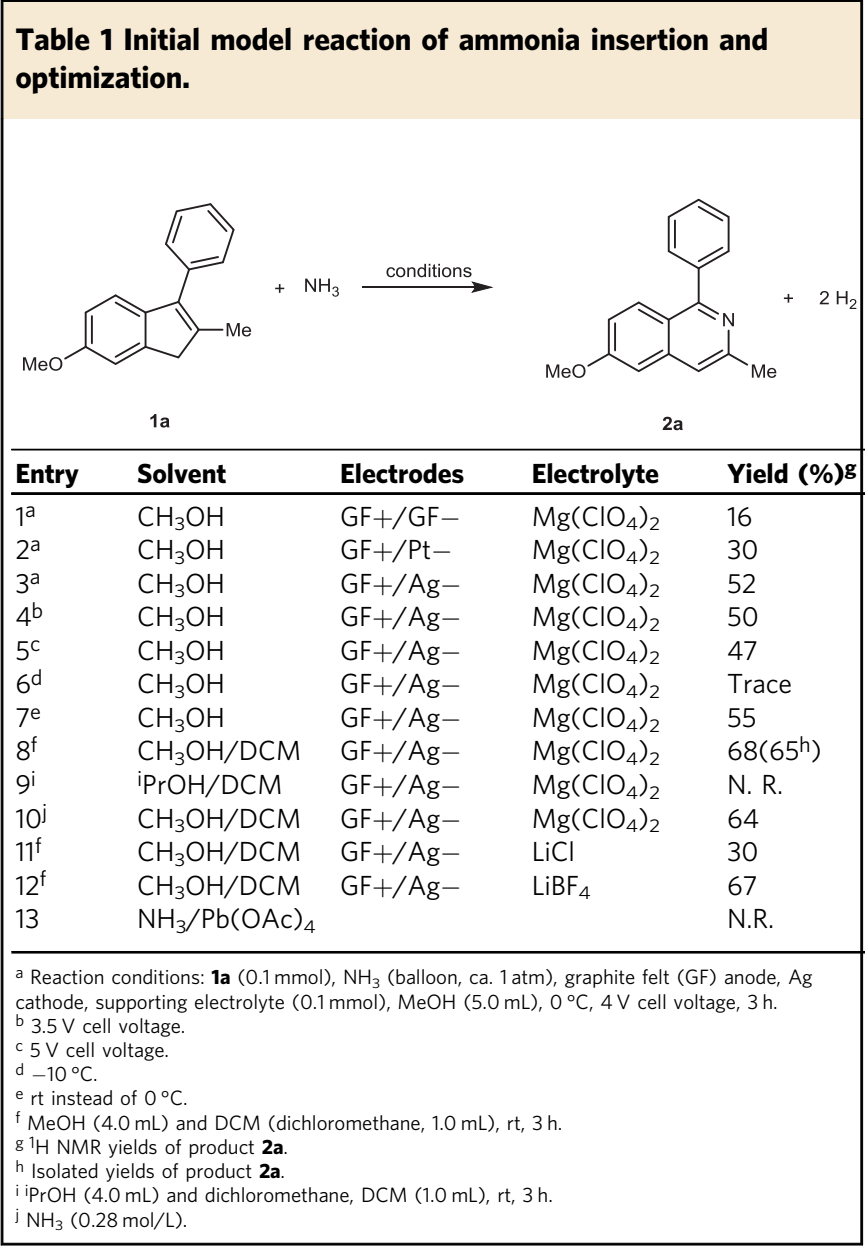

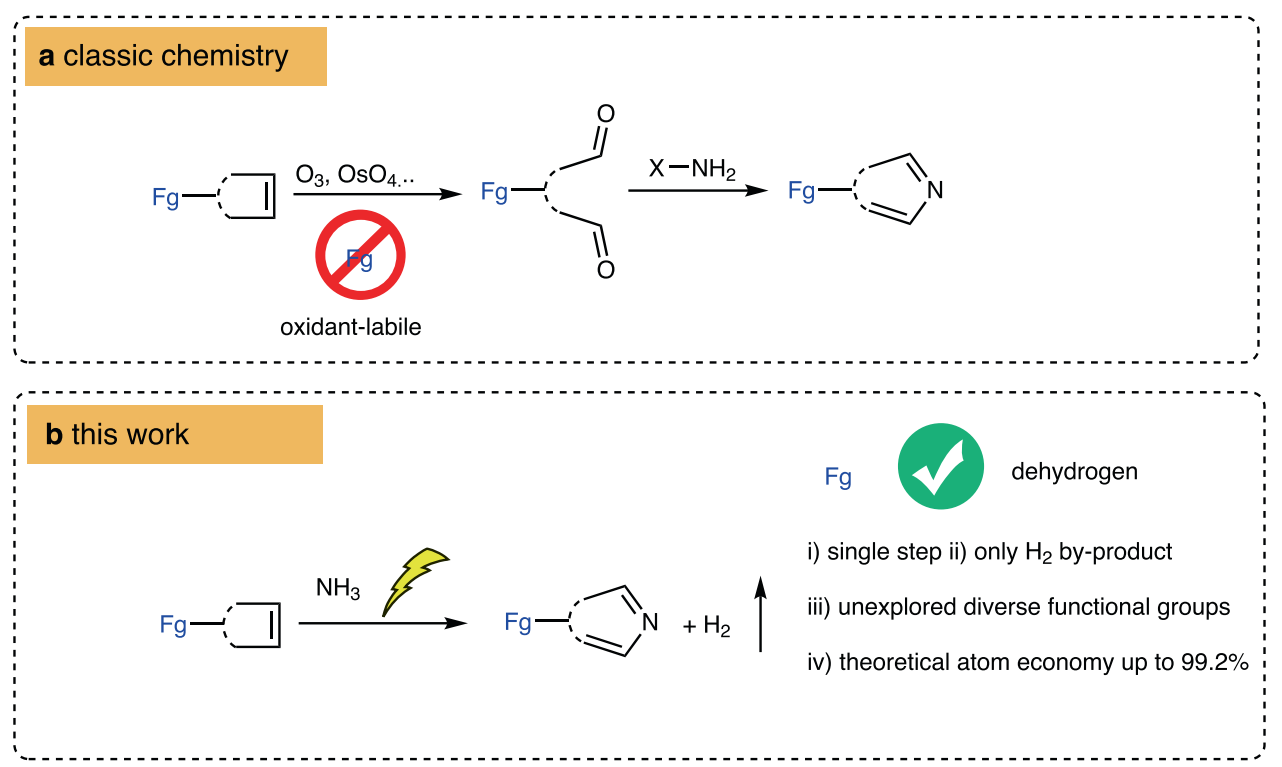

Fig. 1 Comparison of protocols to construct aromatic $\mathbf{N}$-heterocycles from alkenes. a Classic chemistry, oxidation/condensation. $\mathbf{b}$ This work, dehydrogenative insertion of $\mathrm{NH}_{3}$. $\mathrm{Fg}=$ functional groups. 


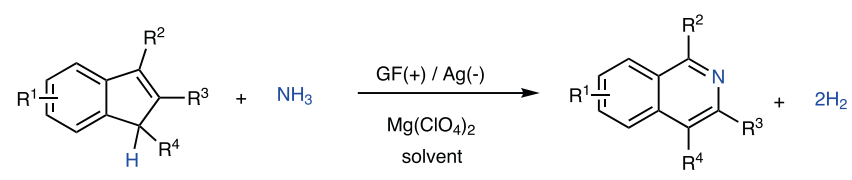

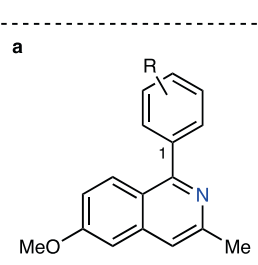

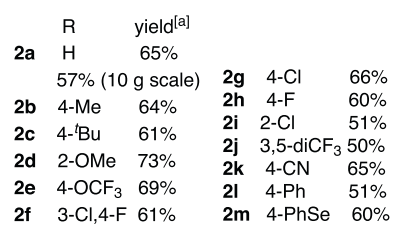<smiles>COc1ccc2c(-c3ccc4c(ccn4C)c3)nc(C)cc2c1</smiles><smiles>[R]c1nc(C)cc2cc(OC)ccc12</smiles><smiles>COc1ccc2c(-c3ccccn3)nc(-c3cccc4ccccc34)cc2c1</smiles>

$20,60 \%$<smiles>COc1ccc2c(-c3ccsc3)nc(C)cc2c1</smiles>

2p, $60 \%$<smiles>COc1ccc2c(-c3ccccc3)nc(-c3cc4cc(OC)ccc4c(-c4ccccc4)n3)cc2c1</smiles>

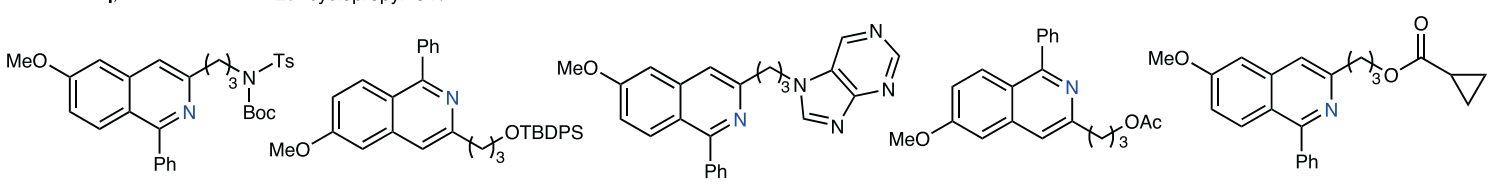

$2 x, 56 \%$

$2 y, 53 \%$

$2 z, 56 \%$

2aa, $74 \%$

$2 a b, 64 \%$<smiles></smiles>

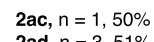

2ae, $62 \%$

2af, $56 \%$<smiles>COc1ccc2c(-c3ccccc3)nc(-c3ccccc3)cc2c1</smiles><smiles>COc1ccc2c(-c3ccccc3)nc(ONC(=O)Nc3ccc(C)cc3)cc2c1</smiles>

2ag, $50 \%$

2ah, $61 \%$

2ai, $58 \%$

2aj, $42 \%$<smiles>c1ccc(-c2cc3ccccc3cn2)cc1</smiles>

2ak, $40 \%$<smiles>COc1ccc(-c2nc(C)cc3ccccc23)c(OC)c1</smiles>

2al, $42 \%$

2am, $66 \%$<smiles>COc1ccc(-c2nc(C)c(C)c3cc(OC)ccc23)cc1</smiles>

2an, $51 \%$

2ao, $43 \%$<smiles>C#CCOc1ccc2c(C)nc(C)c(C)c2c1</smiles>

2ap, 38\%

2aq, $44 \%[$ [b]<smiles>CC1Cc2ccccc2C1c1ccccc1</smiles>

1au no reaction $\quad 1$ av, no reaction

Fig. 2 The insertion of ammonia into various alkenes. a Reaction conditions: graphite felt (GF) anode and $\mathrm{Ag}$ cathode, $1(0.1 \mathrm{mmol}), \mathrm{NH}_{3}$ (balloon, ca. $1 \mathrm{~atm}), \mathrm{Mg}\left(\mathrm{ClO}_{4}\right)_{2}(0.1 \mathrm{mmol}), \mathrm{MeOH} / \mathrm{DCM}=4 \mathrm{~mL} / 1 \mathrm{~mL}$, or $3 \mathrm{~mL} / 2 \mathrm{~mL}, 3.5-4.5 \mathrm{~V}$ cell potential, $\mathrm{rt}, 3-4 \mathrm{~h}$. [a] isolated yields are reported for all cases. [b] reaction conditions: $\mathrm{GF}$ anode and $\mathrm{Ag}$ cathode, 1aq $(0.05 \mathrm{mmol}), \mathrm{Mg}\left(\mathrm{ClO}_{4}\right)_{2}(0.1 \mathrm{mmol}), \mathrm{MeOH} /$ toluene $=3 \mathrm{~mL} / 2 \mathrm{~mL}, 5.5 \mathrm{~V} \mathrm{cell} \mathrm{potential,} \mathrm{rt,} 3 \mathrm{~h}$.

b Substrates did not react. 


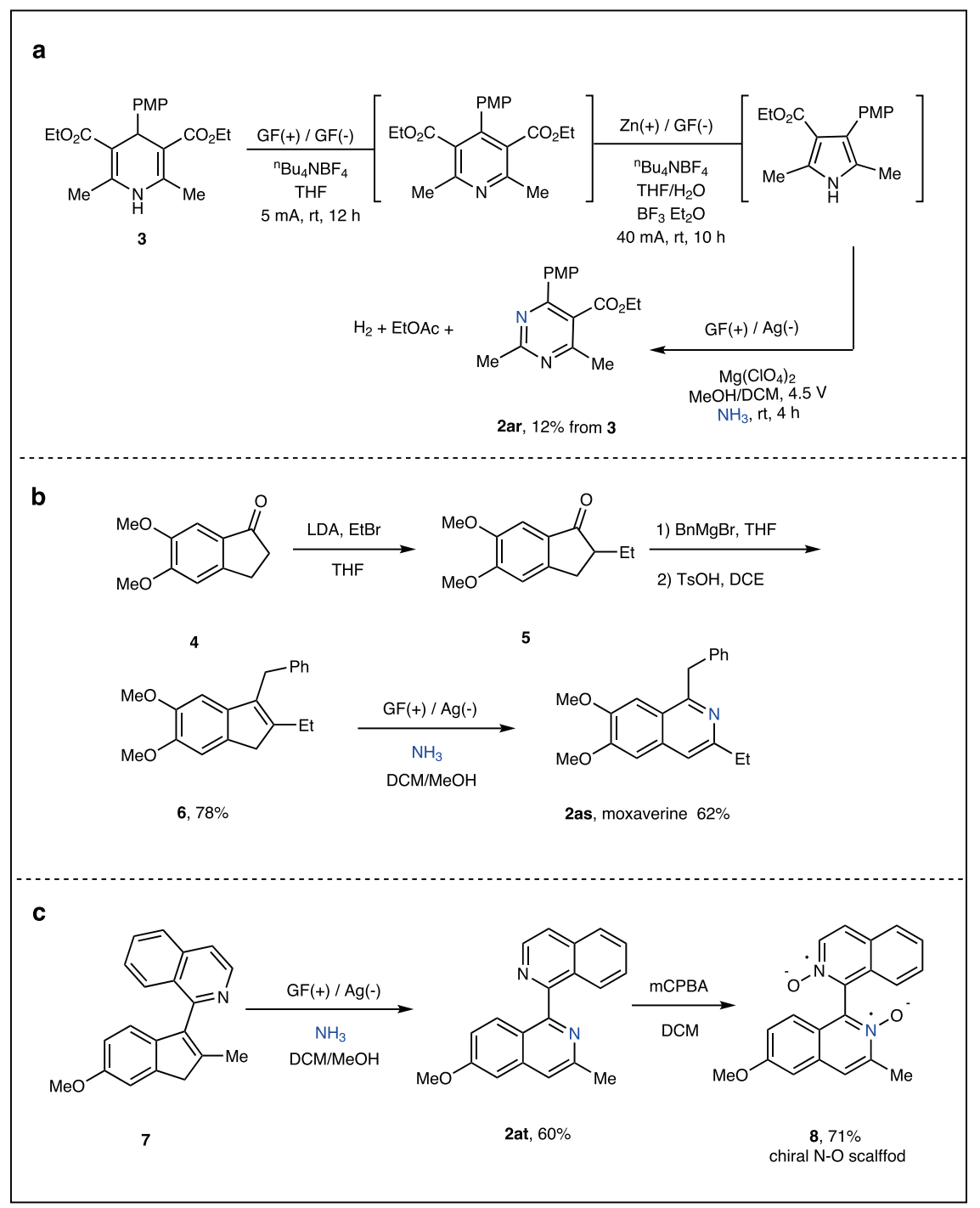

Fig. 3 The application of ammonia insertion protocol. a Three-step electrochemical synthesis of diazine $\mathbf{2 a r}$ from Hantzsch ester 3. b Synthesis of choroidal blood regulator moxaverine 2as. c Synthesis of 6-methoxy-3-methyl-[1,1'-biisoquinoline] 2,2'-dioxide. GF, graphite felt; mCPBA; LDA, lithium diisopropylamide; 3-chloroperoxybenzoic acid, PMP, 4-MeOPh.

corresponding yields were improved to 30 and 52\%, respectively. The decrease (entry 4) and increase (entry 5) in cell voltage slightly decreased the yield. Lowering the reaction temperature to $-10^{\circ} \mathrm{C}$ brought only trace conversion (entry 6). However, the reaction at room temperature could give the desired isoquinoline in comparable yield (entry 7). The application of DCM as a cosolvent could improve the solubility of the substrate and lead to a $65 \%$ isolated yield (entry 8 ). When ${ }^{\mathrm{i}} \mathrm{PrOH}$ was the solvent with dichloromethane (DCM) as the co-solvent, the conversion of alkene was not observed due to the low conductivity (entry 9). Instead of an ammonia atmosphere, a solution of ammonia at a concentration of $0.28 \mathrm{~mol} / \mathrm{L}$ was adequate to give a comparable yield (entry 10). The screening of other supporting electrolytes showed that $\mathrm{LiCl}$ resulted in inferior yields (entry 11 ), and $\mathrm{LiBF}_{4}$ gave acceptable results (entry 12). A reaction using $\mathrm{Pb}(\mathrm{OAc})_{4}$ as the terminal oxidant ${ }^{61}$ with ammonia did not give conversion of the substrate (entry 13, see Supplementary Tables 1 and 2 for more details).

Substrate scope of reaction of insertion of ammonia. With the optimized conditions (Table 1, entry 8), we explored the scope of the other cyclic alkenes (Fig. 2). Products $\mathbf{2 a - 2} \mathbf{m}$ with different aryl groups at the $\mathrm{R}^{2}$ position were obtained in moderate to good yields. In a 10-gram scale reaction, product $2 \mathbf{a}$ was isolated in a similar yield (57\%) to that shown in Table 1 (65\%, entry 6). Next,

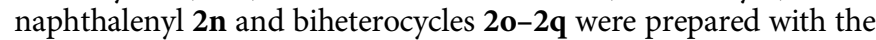
same protocol. The electron-deficient pyridine 20 and electronrich thiophene $\mathbf{2} \mathbf{p}$ and indole $\mathbf{2 q}$ were all compatible. Next, the reactions employing substrates bearing alkyl $\mathrm{R}^{2}$ groups gave the products $2 \mathbf{r}-\mathbf{2 t}$. In the case of $\mathbf{2 t}$, the radical clock cyclopropyl group was intact during the transformation. Next, the other $\mathrm{R}^{3}$ side chains were evaluated using a series of functional groups. Allyl $\mathbf{2} \mathbf{u}$, estrone-derived ether $\mathbf{2} \mathbf{v}$, mercaptophenyltetrazolederived thioether $\mathbf{2 w}$, amide protected with tbutoxycarbonyl (Boc) and p-tolyl sulfonyl (Ts) $\mathbf{2 x}$, silyl ether $\mathbf{2} \mathbf{y}$, and purine $\mathbf{2 z}$ were all robust under these reaction conditions, and the corresponding products were achieved in $50-60 \%$ yield. In addition, substrates $\mathbf{1}$, which incorporated different ester groups, were synthesized as tested under the standard conditions, and the desired products 2aa-2ai were obtained in up to $74 \%$ yield, revealing further tolerance towards Ar-Br 2ag, furan 2ah, and $\mathrm{R}-\mathrm{Cl}$ 2ai groups. A carbamate 2aj was achieved in moderate $42 \%$ yield. Next, the 


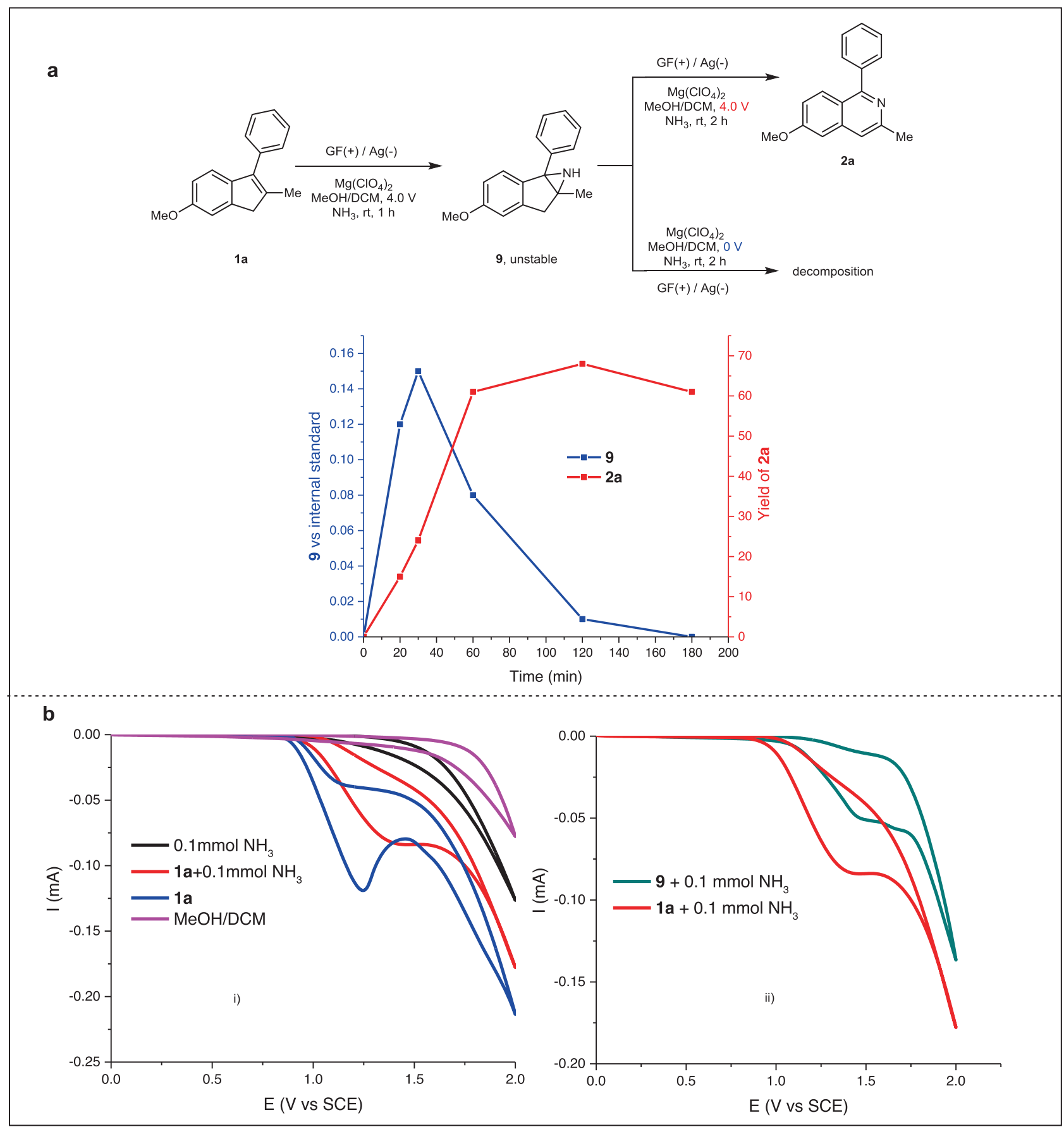

Fig. 4 Experiments investigating the reagents and intermediates. a Investigation and tracking of intermediates $\mathbf{9}$ under different conditions. $\mathbf{b}$ Cyclic voltammetry experiments of reactants and $\mathbf{9}$. GF, graphite felt; DCM, dichloromethane.

indenes 1 with varied substitution patterns was converted to isoquinolines 2ak-2ap. In these cases, the yields were lower partially because of the unidentified side reactions involving $\mathrm{MeOH}$ as a nucleophile. We further explored the substrate scope beyond the indene. Tetraphenyl cyclopentadiene was converted to the corresponding tetraphenyl pyridine 2aq in a single step in $44 \%$ yield. Functional groups, such as alkenes, alkynes, selenides, thioethers, thiophenes ${ }^{62,63}$, and indole ${ }^{64}$, which react with ozone readily, were all tolerated during the transformations. In the example of $\mathbf{2} \mathbf{v}$, a theoretical atom economy of $99.2 \%$ was realized. However, there was a limit on the pattern of substitution. For example, substrates lau and 1av showed that the electron-donating group on the indene backbone and aryl ring on the alkene were important because they were capable of stabilizing the cationic and radical intermediates.

Tandem reaction involving the insertion of ammonia. Subsequently, we explored the insertion of ammonia into alkenes in a three-step tandem electrochemical reaction (Fig. 3a). By employing Hantzsch ester $\mathbf{3}$ as the starting material, tandem electrochemical dehydrogenative oxidation/reductive ring contraction $/ \mathrm{NH}_{3}$ insertion gave 1,3-diazine 2ar without isolation of intermediates. The overall side products for this transformation were ethyl acetate ${ }^{65}$ and hydrogen, and the obtained tetra- 


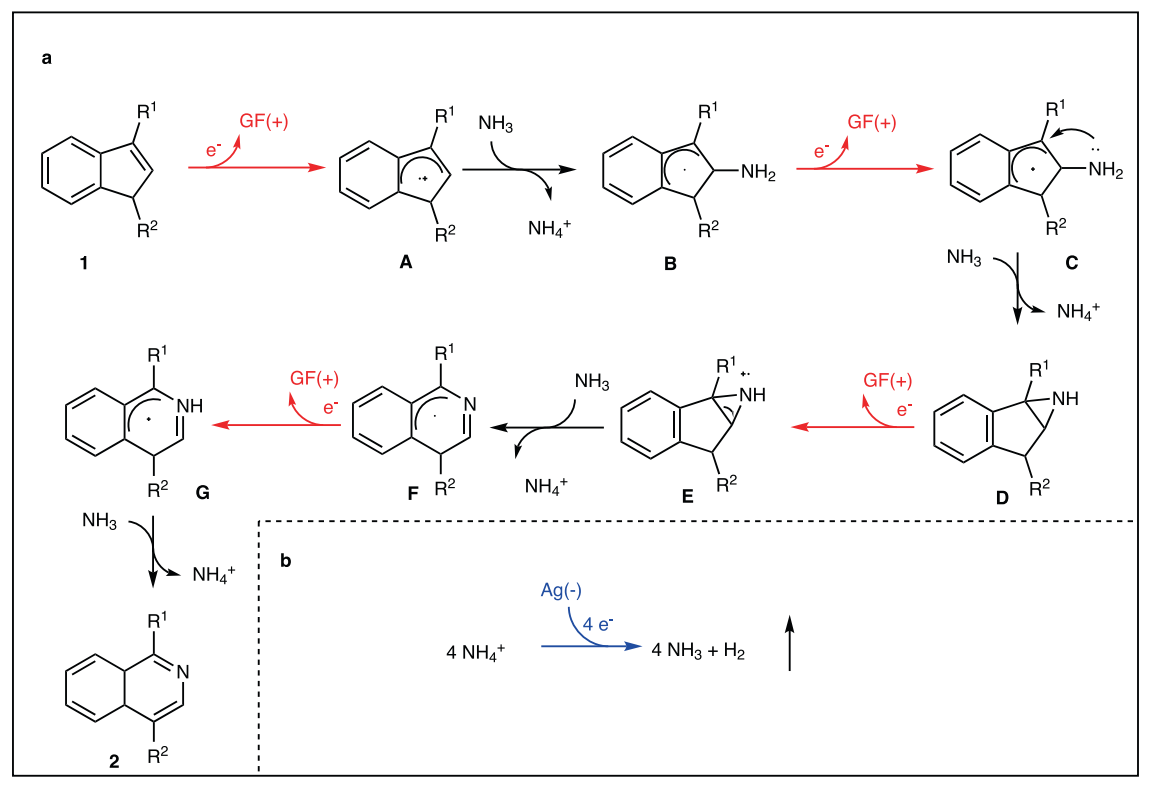

Fig. 5 A plausible reaction pathway involving 4e oxidation. a Anodic reactions converting substrate $\mathbf{1}$ to product $\mathbf{2}$, GF $(+)$ is graphite felt anode. b Cathodic hydrogen evolution.

substituted 1,3-diazine was not accessible by any other methods (see Supplementary Figs. 36 and 37 for more details). With this method, the commercial pharmaceutical compound moxaverine 2as was synthesized in four steps from indanone $\mathbf{4}$ with ammonia insertion as the key step in $62 \%$ yield (Fig. 3b). Next, Compound 7 was converted to unsymmetric bi-quinoline 2at, which was further oxidized to $\mathrm{N}-\mathrm{O}$ oxide with 3-chloroperoxybenzoic acid (mCPBA). The achieved bi- $\mathrm{N}-\mathrm{O}$ oxide 8 was an axial chiral scaffold (Fig. 3c, see Supplementary Fig. 38 for more details) ${ }^{66}$.

Mechanistic studies. Next, experiments under controlled conditions were conducted to gain some information about the reaction pathway (Fig. 4). At first, the reaction of 1a and ammonia was interrupted at an early stage before the full consumption of the starting alkene. An unstable intermediate aziridine 9 was detected, isolated, and characterized. Next, we subjected Compound 9 to the same electrochemical conditions, and the final isoquinoline 2a was produced as the major product. However, when Compound 9 was subjected to the same chemical environment without electricity, decomposition to an unknown complex mixture was observed, and target Compound 2a was not detected at all (see Supplementary Figs. 7-9 for more details). In the kinetic study, the concentration of intermediate 9 reached a maximum at $30 \mathrm{~min}$ and then decreased to full consumption until $180 \mathrm{~min}$. In comparison, product $\mathbf{2 a}$ was generated continuously for $120 \mathrm{~min}$, and then the yield dropped slightly (Fig. 4a, see Supplementary Figs. 10 and 11 for more details). Next, cyclic voltammetry $(\mathrm{CV})$ was performed on the species in the reaction (Fig. 4b). The results revealed that 1a more readily lost electrons than ammonia when it was the sole solute in $\mathrm{MeOH}$ (Fig. 4b-i, blue curve). When 1a and ammonia were exposed to anodic oxidation together, the onset potential $(1.0 \mathrm{~V}$ vs. saturated calomel electrode SCE) of the reactants was similar to that of 1a, but the peak potential shifted to $1.5 \mathrm{~V}$ vs. SCE, suggesting that ammonia affected the electrode environment during electron transfer from 1a to the anode (Fig. $4 \mathrm{~b}-\mathrm{i}$, red curve). Furthermore, it was found that the oxidation of 1a proceeded slightly more readily than the oxidation of the intermediate (9) (Fig. $4 \mathrm{~b}$-ii, see Supplementary Figs. 21-26 for details).
A plausible reaction mechanism. With these observations, we suggest a plausible reaction pathway, shown in Fig. 5. First, the reaction starts with anodic oxidation of alkene $\mathbf{1}$ and the subsequent trapping of cationic radical $\mathbf{A}$ with ammonia (for more details of the radical kinetics, see Supplementary Figs. 15-19). The second oxidation converts the consequent neutral radical $\mathbf{B}$ to cation $\mathbf{C}$, which undergoes annulation to aziridine $\mathbf{D}$. A third electron transfer oxidation of nitrogen during the conversion of $\mathbf{D}$ to $\mathbf{E}$ triggers deprotonation/rearrangement, yielding dihydroisoquinoline radical $\mathbf{F}$. The fourth electron transfer and deprotonation results in the final product 2 . Finally, the evolution of 2 equivalents of hydrogen molecules at the cathode accomplishes the whole electron cycle.

\section{Discussion}

In summary, we developed a direct insertion of ammonia into cyclic alkenes to synthesize aromatic $N$-heterocycles. The reaction utilizes electrochemical hydrogen evolution instead of oxygenation to drive the reaction. The reaction proceeds via electrochemical aziridination and ring rearrangement with up to $99.2 \%$ theoretical atom economy. By avoiding the usage of external oxidants, various functional groups labile towards oxidation were compatible in this transformation. Divergent $\mathrm{N}$-heterocycles are available with this oxidant-free pathway.

\section{Methods}

General procedure for the synthesis of 2. A $10 \mathrm{~mL}$ three-necked heart-shaped flask was charged with the substrate alkene $(0.1 \mathrm{mmol}), \mathrm{Mg}\left(\mathrm{ClO}_{4}\right)_{2}(22.3 \mathrm{mg}$, $0.1 \mathrm{mmol}$ ) and a magnetic stir bar. The flask was equipped with a rubber stopper, graphite felt $(2 \mathrm{~cm} \times 1 \mathrm{~cm} \times 0.5 \mathrm{~cm})$ as the anode and Ag plate $(2 \mathrm{~cm} \times 1 \mathrm{~cm})$ as the cathode. The flask was evacuated and backfilled with ammonia gas three times, and then an ammonia gas balloon was connected to this flask via a needle. Next, anhydrous solvent $(5 \mathrm{~mL})$ was added via syringe. Electrolysis with constant cell potential was carried out at room temperature. The reaction was monitored with TLC and GC-MS, and when it was complete, the mixture was concentrated under reduced pressure. The residue was purified by chromatography on silica gel to afford the desired product (see Supplementary Fig. 1 for more details).

Gram-scale reaction to prepare 2a: A $400 \mathrm{~mL}$ rectangular flask was charged with substrate $1 \mathrm{a}(10.0 \mathrm{~g}, 42 \mathrm{mmol}), \mathrm{LiBF}_{4}(0.60 \mathrm{~g}, 6 \mathrm{mmol})$ and a magnetic stir bar. The flask was equipped with two pieces of graphite felt $(8.5 \mathrm{~cm} \times 6.5 \mathrm{~cm} \times 0.5 \mathrm{~cm}$, $6.5 \mathrm{~cm} \times 6.5 \mathrm{~cm} \times 0.5 \mathrm{~cm})$ as the anode $(2$ pieces $)$ and one piece of silver flake $(6.5 \mathrm{~cm} \times 6.5 \mathrm{~cm} \times 0.5 \mathrm{~cm})$ as the cathode. Two electrodes were separated and fixed 
with a $1.0 \mathrm{~cm}$ stick. The graphite felt anode was attached to a platinum wire, and cathode was attached to a silver wire (see Supplementary Figs. 2-6 for details). The flask was evacuated once and backfilled with gaseous $\mathrm{NH}_{3}$, and $200 \mathrm{~mL}$ of anhydrous $\mathrm{MeOH}$ and $100 \mathrm{~mL}$ of anhydrous DCM were added via syringe. Electrolysis under a controlled cell potential $(8 \mathrm{~V}$ due to the extended distance between anode and cathode) was carried out in a water bath at room temperature. After $14 \mathrm{~h}$, the mixture was concentrated under reduced pressure. The residue was purified by chromatography on silica gel to afford desired product $2 \mathbf{a}(6.0 \mathrm{~g}, 57 \%)$.

\section{Data availability}

The authors declare that all other data supporting the findings of this study are available within the article and Supplementary Information files and are also available from the corresponding author upon request.

Received: 13 July 2021; Accepted: 5 January 2022;

Published online: 20 January 2022

\section{References}

1. Joule, J. A. In Adv. Heterocycl. Chem. 119 (eds Eric F. V. Scriven \& Christopher A. Ramsden) 81-106 (Academic Press, 2016).

2. Vitaku, E., Smith, D. T. \& Njardarson, J. T. Analysis of the structural diversity, substitution patterns, and frequency of nitrogen heterocycles among U.S. FDA approved pharmaceuticals. J. Med. Chem. 57, 10257-10274 (2014).

3. Fremery, M. I. \& Fields, E. K. Amozonolysis of cycloolefins. J. Org. Chem. 29, 2240-2243 (1964).

4. Miller, R. B. \& Frincke, J. M. Synthesis of isoquinolines from indenes. J. Org. Chem. 45, 5312-5315 (1980).

5. Dime, D. S. \& McLean, S. Synthesis of isoquinolines from indenes. J. Org. Chem. 46, 4999-5000 (1981).

6. Quin, L. D. \& Tyrell, J. A. Fundamentals of Heterocyclic Chemistry: Importance in Nature and in the Synthesis of Pharmaceuticals. 344 (John Wiley \& Sons, Inc, 2010).

7. Ito, Y., Hirao, T. \& Saegusa, T. Synthesis of.alpha.,.beta.-unsaturated carbonyl compounds by palladium(II)-catalyzed dehydrosilylation of silyl enol ethers. J. Org. Chem. 43, 1011-1013 (1978).

8. Nicolaou, K. C., Zhong, Y. L. \& Baran, P. S. A new method for the one-step synthesis of $\alpha, \beta$-unsaturated carbonyl systems from saturated alcohols and carbonyl compounds. J. Am. Chem. Soc. 122, 7596-7597 (2000).

9. Diao, T. \& Stahl, S. S. Synthesis of cyclic enones via direct palladium-catalyzed aerobic dehydrogenation of ketones. J. Am. Chem. Soc. 133, 14566-14569 (2011).

10. Izawa, Y., Zheng, C. \& Stahl, S. S. Aerobic oxidative Heck/dehydrogenation reactions of cyclohexenones: efficient access to meta-substituted phenols. Angew. Chem. Int. Ed. 52, 3672-3675 (2013).

11. Jin, X., Koizumi, Y., Yamaguchi, K., Nozaki, K. \& Mizuno, N. Selective synthesis of primary anilines from cyclohexanone oximes by the concerted catalysis of a Mg-Al layered double hydroxide supported Pd catalyst. J. Am. Chem. Soc. 139, 13821-13829 (2017).

12. Wang, M.-M., Ning, X.-S., Qu, J.-P. \& Kang, Y.-B. Dehydrogenative synthesis of linear $\alpha, \beta$-unsaturated aldehydes with oxygen at room temperature enabled by ${ }^{t}$ BuONO. ACS Catal. 7, 4000-4003 (2017).

13. Chen, M., Rago, A. J. \& Dong, G. Platinum-catalyzed desaturation of lactams, ketones, and lactones. Angew. Chem. Int. Ed. 57, 16205-16209 (2018).

14. Chuentragool, P., Parasram, M., Shi, Y. \& Gevorgyan, V. General, mild, and selective method for desaturation of aliphatic amines. J. Am. Chem. Soc. 140, 2465-2468 (2018).

15. Wang, Z., He, Z., Zhang, L. \& Huang, Y. Iridium-catalyzed aerobic $\alpha, \beta$ dehydrogenation of $\gamma, \delta$-unsaturated amides and acids: activation of both $\alpha$ and $\beta-\mathrm{C}-\mathrm{H}$ bonds through an allyl-iridium intermediate. J. Am. Chem. Soc. 140, 735-740 (2018).

16. Hu, R., Chen, F.-J., Zhang, X., Zhang, M. \& Su, W. Copper-catalyzed dehydrogenative $\gamma$-C $\left(\mathrm{sp}^{3}\right)-\mathrm{H}$ amination of saturated ketones for synthesis of polysubstituted anilines. Nat. Commun. 10, 3681 (2019).

17. Teskey, C. J., Adler, P., Gonçalves, C. R. \& Maulide, N. Chemoselective $\alpha, \beta-$ dehydrogenation of saturated amides. Angew. Chem. Int. Ed. 58, 447-451 (2019).

18. Chen, M. \& Dong, G. Platinum-catalyzed $\alpha, \beta$-desaturation of cyclic ketones through direct metal-enolate formation. Angew. Chem. Int. Ed. 60, 7956-7961 (2021).

19. Gnaim, S. et al. Electrochemically driven desaturation of carbonyl compounds. Nat. Chem. 13, 367-372 (2021).

20. Hu, R., Tao, Y., Zhang, X. \& Su, W. 1,2-Aryl migration induced by amide C $-\mathrm{N}$ bond-formation: reaction of alkyl aryl ketones with primary amines towards $\alpha, \alpha$-diaryl $\beta, \gamma$-unsaturated $\gamma$-lactams. Angew. Chem. Int. Ed. 60, 8425-8430 (2021).
21. Huang, D. \& Newhouse, T. R. Dehydrogenative Pd and Ni catalysis for total synthesis. Acc. Chem. Res. 54, 1118-1130 (2021).

22. Li, C.-J. Cross-dehydrogenative coupling (CDC): exploring $\mathrm{C}-\mathrm{C}$ bond formations beyond functional group transformations. Acc. Chem. Res. 42, 335-344 (2009).

23. Scheuermann, C. J. Beyond traditional cross couplings: the scope of the cross dehydrogenative coupling reaction. Chem. Asian J. 5, 436-451 (2010).

24. Yeung, C. S. \& Dong, V. M. Catalytic dehydrogenative cross-coupling: forming carbon-carbon bonds by oxidizing two carbon-hydrogen bonds. Chem. Rev. 111, 1215-1292 (2011).

25. Liu, C. et al. Oxidative coupling between two hydrocarbons: an update of recent C-H functionalizations. Chem. Rev. 115, 12138-12204 (2015).

26. Chen, B., Wu, L.-Z. \& Tung, C.-H. Photocatalytic activation of less reactive bonds and their functionalization via hydrogen-evolution cross-couplings. Acc. Chem. Res. 51, 2512-2523 (2018).

27. Tang, S., Liu, Y. \& Lei, A. Electrochemical oxidative cross-coupling with hydrogen evolution: a green and sustainable way for bond formation. Chem $\mathbf{4}$, 27-45 (2018).

28. Yuan, Y. \& Lei, A. Electrochemical oxidative cross-coupling with hydrogen evolution reactions. Acc. Chem. Res. 52, 3309-3324 (2019).

29. Röckl, J. L., Pollok, D., Franke, R. \& Waldvogel, S. R. A decade of electrochemical dehydrogenative C,C-coupling of aryls. Acc. Chem. Res. 53, 45-61 (2020).

30. Wang, P., Gao, X. L., Huang, P. F. \& Lei, A. W. Recent advances in electrochemical oxidative cross-coupling of alkenes with $\mathrm{H}_{2}$ evolution. Chemcatchem 12, 27-40 (2020).

31. Jiang, Y., Xu, K. \& Zeng, C. Use of electrochemistry in the synthesis of heterocyclic structures. Chem. Rev. 118, 4485-4540 (2018).

32. Kärkäs, M. D. Electrochemical strategies for $\mathrm{C}-\mathrm{H}$ functionalization and $\mathrm{C}-\mathrm{N}$ bond formation. Chem. Soc. Rev. 47, 5786-5865 (2018).

33. Xiong, P. \& Xu, H.-C. Chemistry with electrochemically generated N-centered radicals. Acc. Chem. Res. 52, 3339-3350 (2019).

34. Qiu, Y., Struwe, J., Meyer, T. H., Oliveira, J. C. A. \& Ackermann, L. Catalystand reagent-free electrochemical azole $\mathrm{C}-\mathrm{H}$ amination. Chem. Eur. J. 24, 12784-12789 (2018).

35. Yang, Q.-L. et al. Copper-catalyzed electrochemical C-H amination of arenes with secondary amines. J. Am. Chem. Soc. 140, 11487-11494 (2018).

36. Sauermann, N., Mei, R. \& Ackermann, L. Electrochemical C-H amination by cobalt catalysis in a renewable solvent. Angew. Chem. Int. Ed. 57, 5090-5094 (2018).

37. Morofuji, T., Shimizu, A. \& Yoshida, J.-I. Electrochemical C-H amination: synthesis of aromatic primary amines via $\mathrm{N}$-arylpyridinium ions. J. Am. Chem. Soc. 135, 5000-5003 (2013).

38. Hu, X., Zhang, G., Nie, L., Kong, T. \& Lei, A. Electrochemical oxidation induced intermolecular aromatic C-H imidation. Nat. Commun. 10, 5467 (2019).

39. Liu, K. et al. Electrooxidative para-selective $\mathrm{C}-\mathrm{H} / \mathrm{N}-\mathrm{H}$ cross-coupling with hydrogen evolution to synthesize triarylamine derivatives. Nat. Commun. 10, 639 (2019).

40. Morofuji, T., Shimizu, A. \& Yoshida, J.-I. Heterocyclization approach for electrooxidative coupling of functional primary alkylamines with aromatics. $J$. Am. Chem. Soc. 137, 9816-9819 (2015).

41. Wesenberg, L. J. et al. Metal-free twofold electrochemical C-H amination of activated arenes: application to medicinally relevant precursor synthesis. Chem. Eur. J. 26, 17574-17580 (2020).

42. Zhang, L. et al. Photoelectrocatalytic arene $\mathrm{C}-\mathrm{H}$ amination. Nat. Catal. 2, 366-373 (2019).

43. Wang, J.-H. et al. Regioselective ortho amination of an aromatic $\mathrm{C}-\mathrm{H}$ bond by trifluoroacetic acid via electrochemistry. Org. Lett. 21, 5581-5585 (2019).

44. Niu, L. et al. Manganese-catalyzed oxidative azidation of $\mathrm{C}\left(\mathrm{sp}^{3}\right)-\mathrm{H}$ bonds under electrophotocatalytic conditions. J. Am. Chem. Soc. 142, 17693-17702 (2020).

45. Hou, Z.-W. et al. Site-selective electrochemical benzylic $\mathrm{C}-\mathrm{H}$ amination. Angew. Chem. Int. Ed. 60, 2943-2947 (2021).

46. Shen, T. \& Lambert, T. H. C-H amination via electrophotocatalytic ritter-type reaction. J. Am. Chem. Soc. 143, 8597-8602 (2021).

47. Kong, W.-J., Shen, Z., Finger, L. H. \& Ackermann, L. Electrochemical access to aza-polycyclic aromatic hydrocarbons: rhoda-electrocatalyzed domino alkyne annulations. Angew. Chem. Int. Ed. 59, 5551-5556 (2020).

48. Fu, N., Sauer, G. S., Saha, A., Loo, A. \& Lin, S. Metal-catalyzed electrochemical diazidation of alkenes. Science 357, 575-579 (2017).

49. Shen, T. \& Lambert, T. H. Electrophotocatalytic diamination of vicinal C-H bonds. Science 371, 620-626 (2021).

50. Li, C. et al. Electrochemically enabled, nickel-catalyzed amination. Angew. Chem. Int. Ed. 56, 13088-13093 (2017).

51. Adeli, Y. et al. Electrochemically oxidative C-C bond cleavage of alkylarenes for anilines synthesis. ACS Catal. 9, 2063-2067 (2019).

52. Kawamata, Y. et al. Electrochemically driven, Ni-catalyzed aryl amination: scope, mechanism, and applications. J. Am. Chem. Soc. 141, 6392-6402 (2019). 
53. Walker, B. R., Manabe, S., Brusoe, A. T. \& Sevov, C. S. Mediator-enabled electrocatalysis with ligandless copper for anaerobic Chan-Lam coupling reactions. J. Am. Chem. Soc. 143, 6257-6265 (2021).

54. Siu, T. \& Yudin, A. K. Practical olefin aziridination with a broad substrate scope. J. Am. Chem. Soc. 124, 530-531 (2002).

55. Chen, J. et al. Electrocatalytic aziridination of alkenes mediated by $n$ - $\mathrm{Bu}_{4} \mathrm{NI}$ : a radical pathway. Org. Lett. 17, 986-989 (2015).

56. Li, J. et al. Electrochemical aziridination by alkene activation using a sulfamate as the nitrogen source. Angew. Chem. Int. Ed. 57, 5695-5698 (2018).

57. Ošeka, M. et al. Electrochemical aziridination of Internal alkenes with primary amines. Chem 7, 255-266 (2021).

58. Liu, S. et al. Electrochemical aziridination of tetrasubstituted alkenes with ammonia. CCS Chem. https://doi.org/10.31635/ccschem.021.202100826 (2021).

59. Holst, D. E., Wang, D. J., Kim, M. J., Guzei, I. A. \& Wickens, Z. K. Aziridines synthesis by coupling amines and alkenes via an electro-generated dication. Nature. 596, 74-79 (2021)

60. Kim, J. E., Choi, S., Balamurugan, M., Jang, J. H. \& Nam, K. T. Electrochemical C-N bond formation for sustainable amine synthesis. Trends Chem. 2, 1004-1019 (2020).

61. Narasimhan, K. \& Kumar, P. R. Addition of phthalimido nitrene to substituted cyclopentadienes. Heterocycles 22, 1369-1375 (1984).

62. Bailey, P. S. \& Hwang, H. H. Ozonation of phenyl-substituted thiophenes. J. Org. Chem. 50, 1778-1779 (1985).

63. Andreev, P. Y. Reaction of ozone with five-membered hetarenes in a liquid phase. Russ. J. Appl. Chem. 85, 1395-1398 (2012).

64. Lee, S.-G., WooLim, C., EuiSong, C. \& HanPark, D. Formation of stable solvent-trapped carbonyl oxides from the ozonolysis of indole derivatives. Synth. Commun. 26, 4623-4631 (1996).

65. Liu, X., Liu, C. \& Cheng, X. Ring-contraction of hantzsch esters and their derivatives to pyrroles via electrochemical extrusion of ethyl acetate out of aromatic rings. Green Chem. 23, 3468-3473 (2021).

66. Reep, C., Morgante, P., Peverati, R. \& Takenaka, N. Axial-chiral biisoquinoline $N, N^{\prime}$-dioxides bearing polar aromatic C-H bonds as catalysts in SakuraiHosomi-Denmark allylation. Org. Lett. 20, 5757-5761 (2018).

\section{Acknowledgements}

This work was supported by the National Science Foundation of China (nos. 22071105, 22031008, Xu Cheng) and the Qinglan Project of Jiangsu Education Department (Xu Cheng).

\section{Author contributions}

S.L. carried out the work on optimization of the reaction conditions, exploration of the substrate scope, elucidation of the mechanism and wrote the supplementary information. X.C. conceived and supervised the project and wrote the manuscript.

\section{Competing interests}

The authors declare no competing interests.

\section{Additional information}

Supplementary information The online version contains supplementary material available at https://doi.org/10.1038/s41467-022-28099-w.

Correspondence and requests for materials should be addressed to Xu Cheng.

Peer review information Nature Communications thanks the anonymous reviewer(s) for their contribution to the peer review of this work. Peer reviewer reports are available.

Reprints and permission information is available at http://www.nature.com/reprints

Publisher's note Springer Nature remains neutral with regard to jurisdictional claims in published maps and institutional affiliations.

cc (i) Open Access This article is licensed under a Creative Commons Attribution 4.0 International License, which permits use, sharing, adaptation, distribution and reproduction in any medium or format, as long as you give appropriate credit to the original author(s) and the source, provide a link to the Creative Commons license, and indicate if changes were made. The images or other third party material in this article are included in the article's Creative Commons license, unless indicated otherwise in a credit line to the material. If material is not included in the article's Creative Commons license and your intended use is not permitted by statutory regulation or exceeds the permitted use, you will need to obtain permission directly from the copyright holder. To view a copy of this license, visit http://creativecommons.org/ licenses/by/4.0/.

(C) The Author(s) 2022 